Marquette University

e-Publications@Marquette

Economics Faculty Research and Publications

Economics, Department of

$1-1-1997$

\title{
Heterogeneous Labor in a Simple Ricardian Model
}

John B. Davis

Marquette University, john.davis@marquette.edu

Amitava Krishna Dutt

Published version. "Heterogeneous Labor in a Simple Ricardian Model," in The State of the History of Economics. Eds. James P. Henderson. London: Taylor \& Francis (Routledge), 1997: 56-67. Publisher Link. (C) 1997 Taylor \& Francis (Routledge). Used with permission. 


\title{
HETEROGENEOUS LABOR IN A SIMPIE RICARDIAN MODEL
}

\author{
Jobn B. Davis and Amitava Krishna Dutt ${ }^{1}$
}

\section{INTRODUCTION}

The simple model that derives from Ricardo's Principles of Political Economy and Taxation assumes a three-class economy with landlords who own land, workers who provide labor, and capitalists who accumulate capital (as a wages fund or in the form of fixed capital). In the simple model, diminishing returns to labor arise due to the heterogeneity of land: as the margin of cultivation is extended, labor is used on progressively less-fertile land, which makes labor less productive. The rent, which is determined so that the marginal land earns no rent, goes to landlords by virtue of their monopoly over land ownership. This model, used extensively in the literature (see, for instance, Kaldor 1956; Pasinetti 1960; Samuelson 1959, 1988; Casarosa 1978; Hicks and Hollander 1977) has increased our understanding of the dynamics of growth and distribution first developed informally by Ricardo.

Davis (1993), in examining the implications of Ricardo's addition of a chapter on machinery introduction to the third edition of the Principles, has suggested a modification of Ricardo's original framework in which the role of land and labor as causes of differential productivity and rent are reversed. According to Ricardo's machinery analysis, in the extreme case when machinery is perfectly substitutable for labor, wages cannot rise, and land thus ceases to play an important role in the economy. Suppose, then, that just as there are different soil fertilities, there are also different qualities of workers, which may also be ranked from most to least productive. Then, on Ricardo's reasoning, inframarginal, higher-quality workers would receive rents by virtue of their monopoly ownership of their skills, while the lowestquality workers would find themselves at the margin in the labor force earning no rents. 'This modified model is still Ricardian, because it relies on an inverse relation between rents and profits, but it departs from Ricardo's original class setting by translating the contest between landlords and capitalists into a more modern one between workers and capitalists.

We think this analysis is very much in the spirit of Ricardo's original view, and thus is an opportunity to, as it were, let Ricardo speak about those 
HETEROGENEOUS I.ABOR IN A RICARDIAN MODEL

features of modern economies that closely resemble features of the economy that he himself examined. In this way we of course hope to show the continuing relevance of Ricardo's thinking to modern concerns. But a further goal of the paper is to apply a form of counterfactual analysis to the history of economic thought to elicit bedrock themes in an historical figure's thought. That is, by applying Ricardo's rent theory to different qualities of workers rather than different qualities of land, we show what features of Ricardo's thinking are essential to his reasoning about growth and distribution in contests between capitalists and resource owners, whatever the nature of the resources under the latter's control. This form of counterfactual reasoning contrasts with traditional comparative static analysis, in that rather than vary a system parameter, we vary the context in which the system operates. We believe this method of investigation valuable for history of economic thought analysis, and one which acts to remove dividing lines between the history of economic thought and economic analysis per se.

The paper, then, develops a simple Ricardian model in which the differential productivity of labor arises due to differences in the quality of workers, and in which inframarginal workers appropriate the Ricardian extensive rent. It is our belief that this model is relevant for advanced capitalist economies in which the agricultural sector plays a relatively small role in economic activity, in which land rent is a small fraction of total income, and in which there are significant differences between workers of different types. We also depart from another major assumption of the original Ricardian model which does not appear appropriate to modern conditions; that is, the Malthusian relation between population (and labor supply) growth and the wage rate, in an effort to further adapt Ricardo's thinking to the contemporary world. In our analysis, inframarginal workers earn rents in addition to wages, but this makes them no more likely to reproduce their ranks than marginal, no-rent workers.

One way of understanding our analysis is in terms of the difference between formal and informal sectors in developed market economies. In the formal sector workers are supported by a wage fund determined by the past accumulation of capitalists. Workers in the informal sector, on the other hand, depend upon a variety of subsistence activities that in many instances make use of markets, though no accumulated wage fund is involved. We think this way of approaching Ricardo does more justice to his thinking than crude Malthusian interpretations of worker subsistence that seem to suggest that workers are always on the edge of survival. On our understanding, workers may be drawn from the informal sector into the formal sector when capital accumulates faster than population growth. In addition, this approach suggests that workers in the informal sector have only fewer skills than do workers in the formal sector, so that the dividing line between the formal and informal sectors only picks out one point on a skill-productivity continuum.

Heterogeneous labor models already exist in both the neoclassical and 


\section{JOHN B. DAVIS AND AMITAVA KRISHNA DUTT}

neo-Marxist literatures. Neoclassical theorists have developed adverse selection models in connection with efficiency wage and dual labor market theories to show how some workers are paid above competitive wages because of qualities as workers that make them more valuable to firms (Bulow and Summers 1986; Weiss 1991). Neo-Marxist models date back to debates in the 1970 s over the labor theory of value, and whether Marx's theory of exploitation can be developed to explain unequal rates of exploitation across different class fractions (Morishima 1978; Bowles and Gintis 1978). 'The Ricardian model developed here, however, makes a contribution distinct from both of these approaches in its focus on growth and distribution. We think that the importance of these issues justifies both the re-examination of Ricardo's original argument along the lines suggested by the added machinery chapter, and the application of the model to contemporary policy concerns.

The model is presented in the next section, and then elaborated in two versions: first, for a world with unemployment, and second, for a world with full employment. In the subsequent section we consider important policy implications for both versions of the model by looking at the effects of two possible developments that might be the outcome of social policy: first, changes in the inequality amongst workers that may arise from policies that influence worker endowments in human capital, our proxy for quality; second, changes in the rate of population growth that may arise from policies that influence migration or natural population growth. The paper is thus Ricardian in not only using Ricardian assumptions to model the economy, but also in succumbing to the Ricardian vice of drawing policy conclusions from simple analytical constructions. The concluding section comments on the extension of Ricardo's growth and distribution thinking to the modern world.

\section{A SIMPLE MODEL}

Consider a closed economy which produces one good with only one factor of production, labor. Labor is heterogeneous in the sense that different types or qualities of labor have different levels of productivity. 'This heterogeneity may be thought to arise because of differences in the endowments of something we call, for lack of a better expression, human capital. We suppose that, upon entering the labor force, workers' endowments are essentially fixed. Differences in worker endowments we attribute to differences in families' abilities to support education and training. Such differences may range from differences in acquired skill and ability to differences in such things as tendencies toward absenteeism and job commitment. Whatever these qualities may be, moreover, the distribution of qualities of labor is taken to proxy the distribution of wealth across families.

For simplicity, we assume that $y(n)$, the productivity of the $n$th worker, is given by the simple linear function 
selec-

heor-

ise of

$\checkmark$ and

in the

ploit-

differ-

Irdian

th of

at the

irdo's

apter,

two

with

solicy

f two

first,

sthat

rality;

from

per is

1 the

solicy

ction

ng to

actor types neity omethat, ixed. idies' from ;s as hese in to $e r$, is

HETEROGENEOUS LABOR INA RICARDIAN MGDEI

$$
y(n)=\alpha_{0}+\alpha_{1} \nu(n)
$$

where $\alpha_{i}$ are positive constants. We assume that workers can be ranked from most productive to least productive according to their respective endowments of human capital in descending order, as follows:

$$
\nu(n)=\beta_{0}-\beta_{1} n
$$

where the $\beta_{1}$ are positive constants and $n$ is the worker index. Linearity in the ranking of skill levels is a simplification which can be eased without significant changes in the analysis. Using equations (4.1) and (4.2), the marginal product function for this economy is thus seen to be given by

$$
y(n)=\left(\alpha_{0}+\alpha_{1} \beta_{0}\right)-\alpha_{1} \beta_{1} n
$$

This is shown as the downward-sloping line in Figure 4.1.

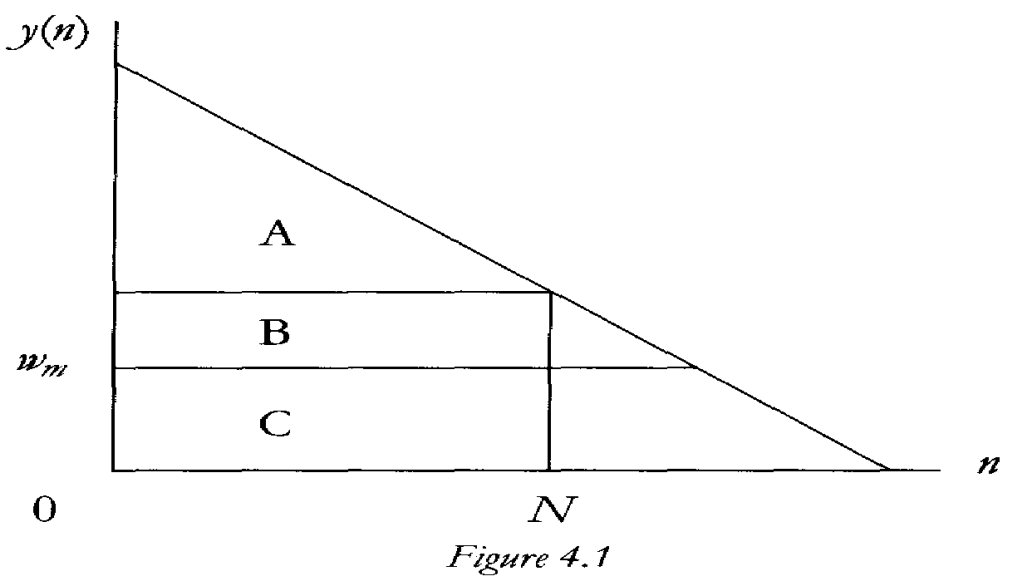

For any given level of employment, $N$, the Ricardian (extensive) rent accruing to worker $n$ is given by

$$
r(n)=y(n)-y(N)
$$

The wage received by worker $n$ is given by

$$
w(n)=r(n)+w_{m}
$$

where $w_{m}$ is the wage received by the marginal worker, $N$. The total wage received by all workers is given by

$$
W(N)=\int_{0}^{N} \nu(n) d n
$$

which, using equations (4.3) through (4.5) is given by

$$
W(N)=\frac{1}{2} \alpha_{1} \beta_{1} N^{2}+w_{{ }_{m}} N
$$


JOHN B. DAVIS AND AMITAVA KRISHNA DUTT

Total profit when $N$ workers are employed is given by

$$
P(N)=\int_{0}^{N} y(n) d n-W(N)=\left[\alpha_{0}+\alpha_{1} \beta_{0}-\alpha_{1} \beta_{1} N-w_{m}\right] N
$$

In Figure 4.1, the total wage bill is given by the sum of areas $A$ and $C$, and total profit is given by area $B$.

Workers consume all of their income, while capitalists who receive profits save a fraction, $s$, of their profits. All saving is automatically invested in this Ricardian Say's Law world.

At a point in time - which we call the short period - we take the wages fund, $W$, to be given as a result of past accumulation. The wages fund approach can be interpreted to be a simple characterization of credit constraints in modern economies. In the long period the change in the wages fund is determined by the level of investment in the economy, so that

$$
\frac{d W}{d t}=s P(N)
$$

We now consider two versions of the model. In one, we assume that the wage of the marginal worker, $w_{m}$, is given, ${ }^{2}$ and the level of employment, $N$, is determined to use up the entire wages fund. We assume that the supply of labor is always greater than $N$, and call this the model with unemployment. In the other version, the level of employment, $N$, is given at a point in time, and the wage schedule varies to clear the market for labor, given the wages fund. We call this the full-employment model.

In the unemployment model we use equation (4.7), with fixed values of $W$ and $w_{m}$, to determine the short-period equilibrium value of $N$, given by

$$
N=\frac{\sqrt{\left(w_{m}^{2}+\alpha_{1} \beta_{1} W\right)-w_{m}}}{\alpha_{1} \beta_{1}}
$$

If we substitute this value of $N$ into equations (4.8) and (4.9) we obtain an equation of motion for $W$ which states that $d W / d t$ depends only on $W$ and the parameters of the model. This equation traces the evolution of $W$ over time and shows that the economy attains a stationary state (or long-period equilibrium) at which $d W / d t=0$, which implies, from equations (4.8) and (4.9) that the stationary-state value of $N$ is given by

$$
N=\frac{\alpha_{0}+\alpha_{1} \beta_{0}-w_{m}}{\alpha_{1} \beta_{1}}
$$

This value is shown in Figure 4.2 by the level of $n$ at which the $w_{m}$ line intersects the marginal product schedule, denoted by $N_{s}{ }^{3}$

The stability of this stationary-state equilibrium is ensured by the fact that at equilibrium, $d(d W / d t) / d W=s(d P / d N)(d N / d W)<0, d N / d W>0$ from equation (4.10), and $d P / d N<0$ at equilibrium. At long-run equilibrium profits are squeezed to zero, and accumulation comes to a halt. 
HETEROGENEOUS LABOR IN A RICARDIAN MODEL.

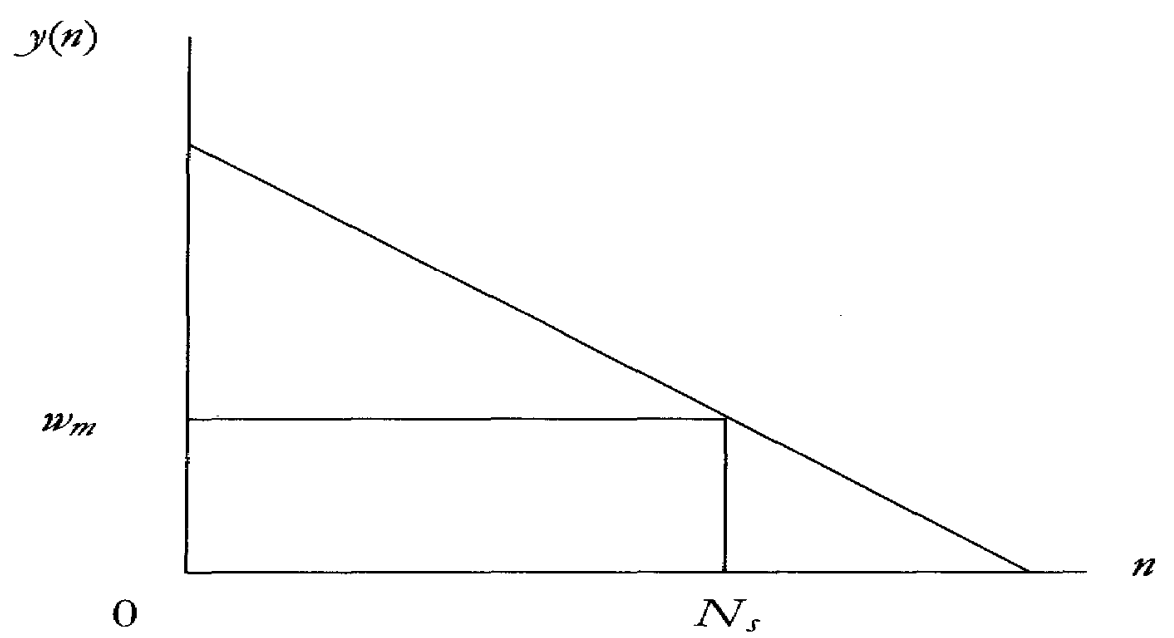

Figure 4.2

In the full-employment model, in the short period $w_{m}$ is determined from equation (4.7), given values of $W$ and $N$. The equilibrium value of $w_{m}$ is given by

$$
w_{n}=\frac{W}{N}-\frac{1}{2} \alpha_{1} \beta_{2} N
$$

Substituting this into the expression for profits, given by equation (4.8), we obtain

$$
P(N)=\alpha_{0}+\alpha_{1} \beta_{0}-\frac{1}{2} \alpha_{1} \beta_{1} N^{2}-W
$$

which we assume to be positive for the initial level of $W$. We assume that the supply of labor, given by $N$, does not change over time. The wages fund changes over time in the manner shown by the equation of motion for $W$ given by substituting equation (4.13) into equation (4.9). Since $N$ is constant, $W$ rises over time till $P(N)$ becomes zero, which occurs when

$$
w_{m}=\alpha_{0}+\alpha_{1} \beta_{0}-\alpha_{1} \beta_{1} N
$$

which is the stationary-state wage of the marginal worker.

\section{SOME IMPLICATIONS OF THE MODEL}

This section examines important policy implications for both versions of the model advanced in the previous section in regard to developments that might be the outcome of social decisions that affect worker inequality and levels of migration. 
JOHN B. DAVIS AND AMITAVA KRISHNA DUTT

Effects of a change in inequality amongst workers

Inequality amongst workers is due to differences in their endowments of human capital, which in turn we have taken to be due to differences in family wealth and ability to support education and training. We can accordingly examine changes in worker inequality by allowing for changes in the distribution of endowments among workers that are the product of policies that differentially affect families' wealth levels and ability to educate and train children. For example, changes in tax laws and government-supported college loan programs may directly affect the distribution of endowments among workers. But more generally, policies that affect incomes may also affect the resources that families are able to commit to training and education.

We model changes in inequality amongst workers by changing the slope and intercept of the $\nu(n)$ curve. To keep total endowments constant when we change only the degree of inequality we must rotate the curve in a manner which satisfies some conservation principle. A natural way to parameterize the degree of equality with $N_{1}$ workers is with the parameter $\theta$ in the equation

$$
\nu(n)=\left(\beta_{0}-\theta\right)-\left(\beta_{1}-2 \frac{\theta}{N_{1}}\right) n
$$

where increases in $\theta$ denote increases in equality. This keeps constant the total endowment of human capital for the $N_{1}$ workers.

The effect of such a change in the $v(n)$ function is to change the marginal product curve given by $y(n)$. For the full-employment model the effect is straightforward. As shown in Figure 4.3, the marginal product curve rotates

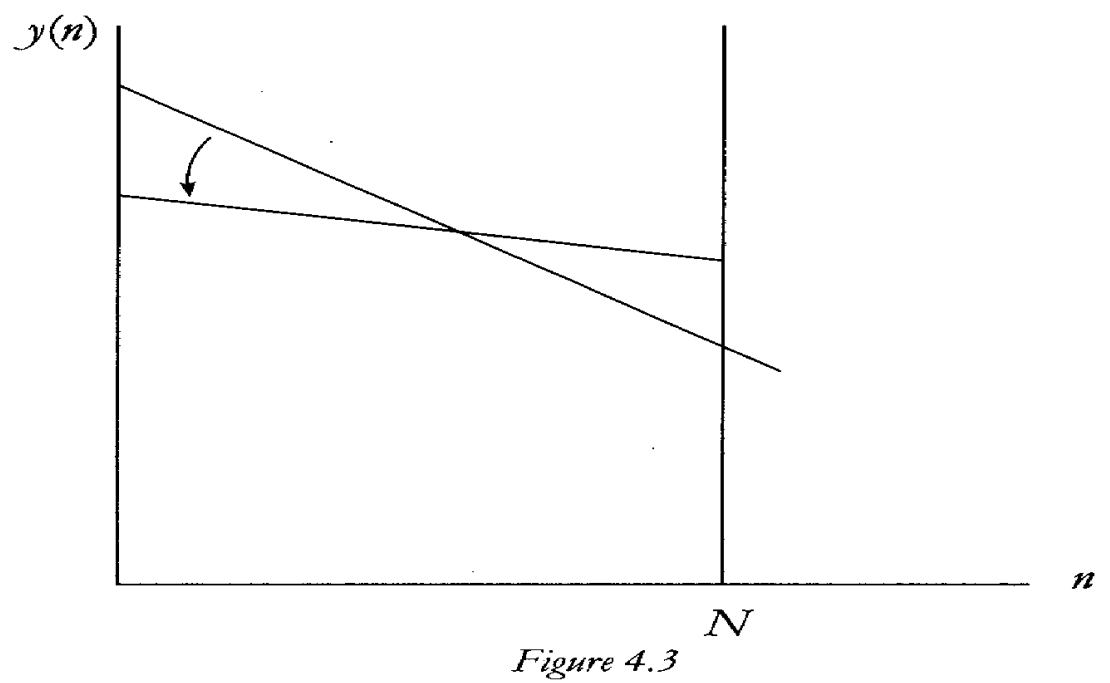




\section{HETEROGENEOUS IABOR IN A RICARDIAN MODEI.}

downward, keeping the area under it constant for $N$ workers. Total product remains unchanged while the distribution of wages adjusts towards greater equality, mirroring the change in the distribution of endowments.

The effect in the model with unemployment is more interesting. Here, since the level of employment can and does change, it is necessary to decide on the appropriate number of workers for which the total endowment is to be held constant. In this case it is appropriate to hold total endowments constant for the total number of workers who will be employed in at least one of the two periods, before and after the change in distribution (in longperiod equilibrium).

The first point to note here is that any change in the $\nu(n)$ curve which increases the endowment of human capital of the marginal worker will change the $y(n)$ curve in such a way that it will intersect the $w_{m}$ line at a higher $N$. This implies that the level of employment with a greater degree of equality will be higher, at $N_{2}$ in Figure 4.4, than at $N_{1}$, the initial equilibrium.

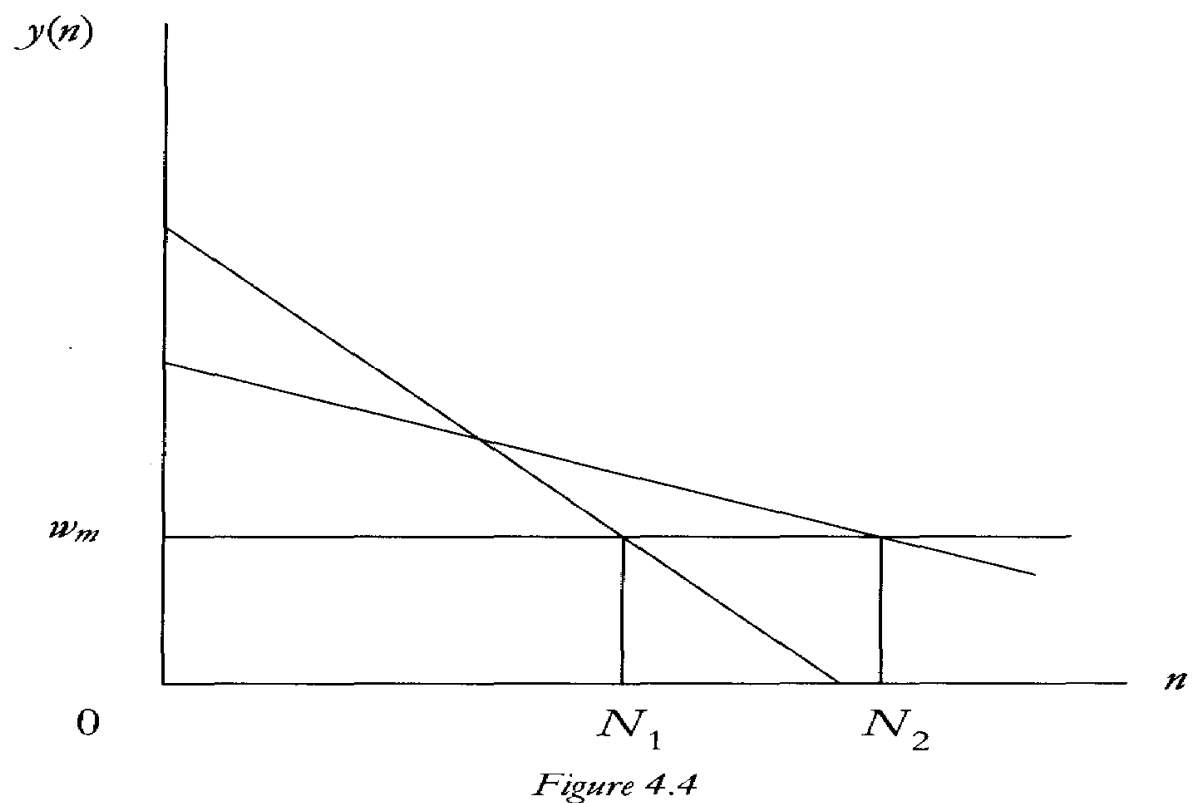

This also implies that the $y(n)$ curve should be rotated so that the area under the two marginal curves between $\mathrm{O}$ and $N_{2}$ must be the same, to keep the total endowments of $N_{2}$ workers constant.

The short-period impact of a rise in equality measured by a rise in $\theta$ will be a rise in the level of employment. This occurs because the wages fund required to hire $N_{1}$ workers with the new $y(n)$ line is less than with the old, since the area under the new curve up to $N_{1}$ is smaller than under the original curve (this is because the areas under the curves are the same if one goes to 
JOHN B. DAVIS AND AMITAVA KRISHNA DUTT

the level $N_{2}$, as pointed out in the previous paragraph), and also since there will be a profit component under the new curve, which was not the case with the old curve (because we were initially at a stationary state with zero profits). Since profits emerge, capitalists will accumulate and employment will increase over time till the new stationary state is attained at $N_{2}$.

Compared to the initial stationary state there will not only be a rise in employment and thus a fall in unemployment, but also a rise in total output. This can be seen from the fact that the area under the original curve between 0 and $N_{1}$ is less than the area under the original curve between 0 and $N_{2}$ which is equal to the area under the new curve between 0 and $N_{2}$. The reason for the increase in output is that workers who were previously unemployable because of their low endowments of human capital, given the institutionally given minimum wage $w_{m}$, are now employable because of their higher productivity and contribution to the increase in total output. Distribution and the total level of activity are thus positively related.

\section{Effects of population growth}

The effects of population growth can also be examined in the model. We think of population growth as being due to either migration policy or policies aimed at altering natural population growth. The former case can have both short-run and long-run impacts; in the latter case we consider long-run impacts, and assume that new people become new workers. The analysis of population growth in our framework requires us to consider not only the growth of total population, but also possible changes in the structure of the population in terms of endowments. A neutral assumption would be a proportional increase in the number of workers of each type. Thus if we imagine that initially there were $k$ workers of each type, and allow the number of each type of worker to increase by the same amount, the $\nu(n)$ curve would become flatter, rotated around the vertical intercept. This can be formalized in terms of a fall in the coefficient $\beta_{1}$; the total number of workers in the economy would rise by the same rate at which $\beta_{1}$ falls.

In the case with full employment, total employment and total output increases with the rise in population at the stationary state. Since output is constrained by the labor supply, it should not be surprising that an increase in labor supply also increases output.

In the case with unemployment, a rise in population increases output and employment in the short period as well as in the long period, as shown in Figure 4.5. Because of the shift in the $v(n)$ curve, the $y(n)$ curve shifts in a similar manner. The initial wage fund, $A B N_{1} O$, is bigger than the wage fund required to hire $N_{1}$ workers after the shift, given by $A D E+w_{m} B N_{1} O$ (since $\left.A D E<A B w_{m}\right)$. Thus in the short period more workers than $N_{1}$ can be hired with the initial wage fund (although this must be less than $N_{2}$ since $\left.A B N_{1} O<A F N_{2} O\right)$. Since positive profits emerge in the short period, capital 
HETEROGENEOUS LABOR IN A RICARDIAN MODEL

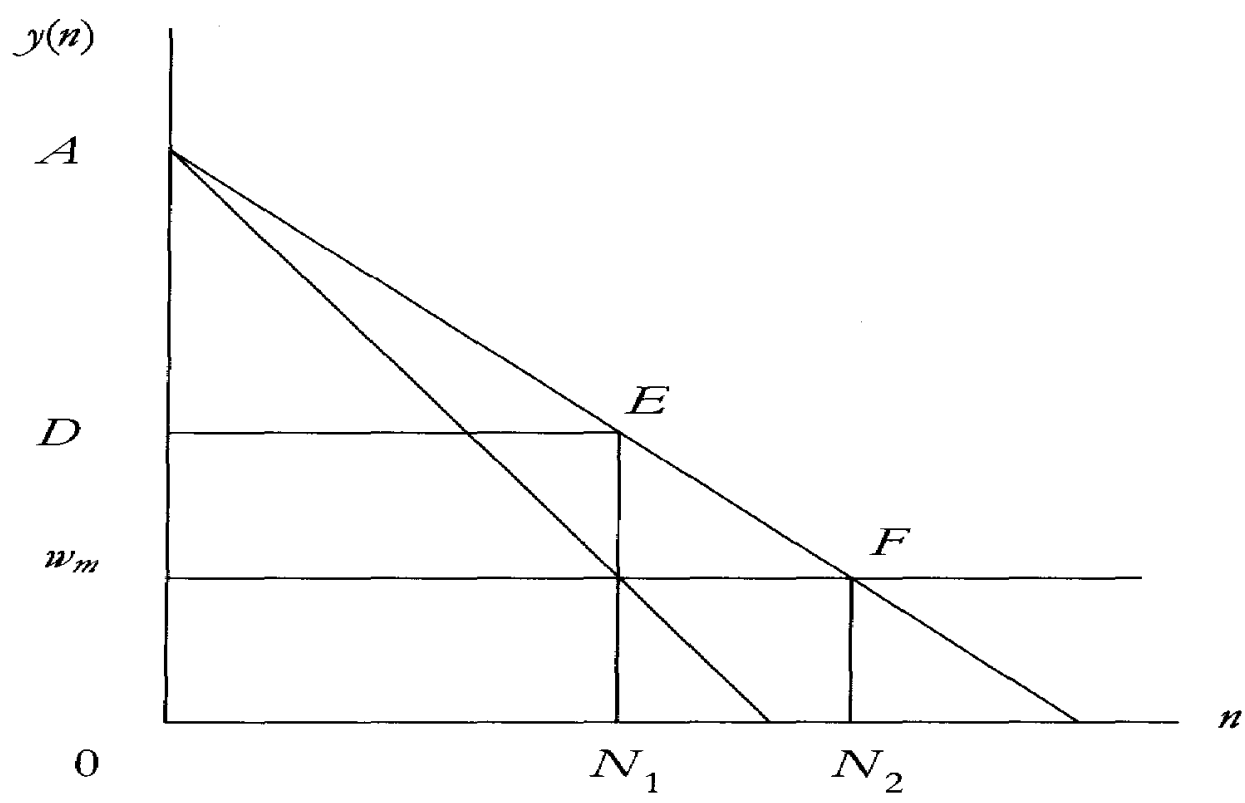

Figure 4.5

in the form of the wages fund will be accumulated in the long period, so that employment will increase to $N_{2}$ in the new stationary state. The original workers, who experience a decline in their wage in the transition phase (and in some cases a loss of jobs), receive the same wages as they did earlier at the new stationary state. Thus even in a model in which labor is not constrained by labor supply (since there is unemployed labor), an increase in population will increase total output. This result does not depend on our assumption that the supply of each kind of labor increases equiproportionately; all we require is that the supply of labor of the types which were previously employed increase.

\section{CONCLUSION}

Our simple Ricardian model which interchanges the roles of land and labor in the original Ricardian model provides a potentially useful way of modeling an economy with labor heterogeneity. Although we have considered a very simple version of the model with only one factor of production, and examined only a few of its implications, we find that the model does produce some interesting results regarding the relationship between output and distribution and regarding the effects of changes in inequality and population growth in economies with unemployment and institutionally determined minimum wages. Specifically, policies that reduce the inequality amongst 
workers, such as might come about from tax law changes or increased support for college loan programs, and policies that affect labor supply, either naturally or through migration, both increase employment and output. In the case of policies affecting labor supply, this is true in both the short run and the long run, though wages and perhaps employment for alreadyemployed workers may fall in the transition period before returning to their original level in the new stationary state.

Of course, in the first two editions of his Principles Ricardo was not directly concerned with employment and unemployment, and his attention to the subject in the chapter on machinery introduction in his third and last edition was limited. Yet in addition to his well-known advocacy of corn law repeal, he was also an active defender of parliamentary reform and the secret ballot, and, according to recent commentators, made a "quite sophisticated argument for democratic citizenship as a prerequisite for economic progress" (Milgate and Stimson 1991, 18). This suggests that he took seriously policies that might enhance employment and the conditions of workers, and lends support for the heterogeneous labor modification and extension of his model of growth and distribution developed here. We believe that this development of the model helps to open contemporary Ricardian approaches to important social policy issues, and demonstrates how Ricardo's ideas continue to be relevant when introduced into new contexts.

\section{NOTES}

1 The authors are grateful to Allin Cottrell and Spencer Pack for comments on an earlier version of this paper.

2 This model is more Ricardian (see Pasinetti 1960) in nature than the subsequent one. Some Ricardian models, however, take the level of employment to be given at a point in time, and allow the short-period wage to be determined (at a level different from the subsistence one) by supply and demand (see Casarosa 1978, and Hicks and Hollander 1977). Malthusian population dynamics then take over in the long run, ensuring that the wage rate is at the subsistence level in the long run. Since in our framework we are assuming away Malthusian dynamics, we follow the fixed-wage approach. The alternative model allows the wage to be determined by supply and demand.

3 We assume that the supply of labor is large enough so that full employment is not reached at a level below this amount; alternatively, we assume that labor supply rises endogenously through some unspecified mechanism.

\section{REFERENCES}

Bowles, S. and Gintis, H. (1978) "Professor Morishima on heterogeneous labour and Marxian value theory," Cambridge Journal of Economics 2 (September): 311-14.

Bulow, J. and Summers, L. (1986) "A theory of dual labor markets with application to industrial policy, discrimination and Keynesian unemployment," Journal of Labor Eiconomics 4: 376-415. 


\section{HETEROGENEOUS LABOR IN A RICARDIAN MODEI.}

Casarosa, C. (1978) "A new formulation of the Ricardian system," Oxford Eiconomic Papers, March.

Davis, J. B. (1993) "Ricardo's theory of profit and the third edition of the Principles," Journal of the History of Economic Thought 15 (Spring): 90-106.

Hicks, J. R. and Hollander, S. (1977) "Ricardo and the Moderns," reprinted in J. Hicks, Classics and Moderns: Collected Essays on Economic Theory, vol. III, Cambridge, MA: Harvard University Press, 1983.

Kaldor, N. (1956) "Alternative theories of distribution," Revien of Economic Studies, 23(2): 83-100, reprinted in N. Kaldor, Essays on Value and Distribution, London: Duckworth, 1960 .

Milgate, M. and Stimson, S. (1991) Ricardian Politics, Princeton, NJ: Princeton University Press.

Morishima, M. (1978) "S. Bowles and H. Gintis on the Marxian theory of value and heterogeneous labour," Cambridge Journal of Economics 2 (September): 305-9.

Ricardo, D. (1821) On the Principles of Political Economy and Taxation, ed. P. Sraffa, -Cambridge: Cambridge University Press, 1951.

Pasinetti, L. L. (1960) "A mathematical reformulation of the Ricardian system," Revien of Economic Studies 27 (February): 78-98, reprinted in L. Pasinetti, Gronth and Income Distribution: Essays in Economic Theory, Cambridge: Cambridge University Press, 1974.

Samueison, P. A. (1959) "A modern treatment of the Ricardian economy: $I$. The pricing of goods and of labor and land services," Quarterly Journal of Economics 73 (February): 1-35, reprinted in J. Stiglitz (ed.), Collected Scientific Papers of Paul $A$. Samuelson, vol. 1, Cambridge, MA: MIT Press.

Samuelson, P. A. (1988) "Mathematical vindication of Ricardo on machinery," Journal of Political Economy $96(2): 274-82$.

Weiss, A. (1991) Efficiency Wages, Models of Unemployment, Layoffs, and Wage Dispersion, Oxford: Clarendon Press. 